\title{
CARCINOMA OF THE MALE BREAST
}

\section{A Case Report and Review of the Literature}

\author{
R. T. H. Marsden, M.B., B.S. \\ Lately House Surgeon, Middlesex Hospital, London*
}

Carcinoma of the male breast is rare and is seen one hundred times less often than carcinoma of the female breast. Simultaneous bilateral carcinomata are unusual even in the female breast, and Paget's disease is not a common complication. It seemed worth, therefore, recording a case of simultaneous bilateral carcinomata, one side showing Paget's disease, in a man, because this combination must be of extreme rarity.

\section{Case Report}

S. B., a man of 54 (Middlesex Hospital, Reg. No. K.49196), presented with a swelling in each breast which he had noticed for four weeks. The right nipple had bled intermittently for six months sufficiently to stain his vest. The left breast was slightly tender. Examination showed the right breast to contain a lump $\frac{3}{8}$ in. diameter with slight but definite skin attachment and pressure produced a scanty blood-stained discharge. Deep to the left nipple was a hard mass, $I_{2} \frac{1}{2}$ in. in diameter, attached to the nipple but not to the underlying muscle. The left nipple showed typical appearances of Paget's eczema. The left axilla contained two enlarged hard nodes but the right axilla was normal.

On 16.1.62 the lump in the right breast was excised and a rapid section showed the presence of carcinoma. Because there were bilateral carcinomata and because the marked involvement of the nodes in the left axilla made it seem that a left radical mastectomy would be unlikely to eradicate the disease on this side, a wide bilateral simple mastectomy with skin grafts was performed. The patient's post-operative course was satisfactory and a full course of radiotherapy to the left axilla, supraclavicular region and internal mammary chain was begun 14 days later, a dose of between 4,000 to 4,500 rads being delivered over a period of 40 days. Histology showed invasion of both breasts by spheroidal cell carcinoma with Paget's disease of the left nipple.

When last seen, four months after his operation, the patient was well and there were no signs of recurrence locally or on chest X-ray.

\section{Incidence}

Carcinoma of the male breast was reported by the Registrar General as the cause of death in only 63 men in -England and Wales in 1960. This represents three deaths per million live population, as compared with 383 deaths per million live population in women, and is $0.8 \%$ of all deaths from breast cancer. This agrees with the figures from reported series which vary from $0.8 \%$ to $1.2 \%$ of all carcinomas of the breast (Speese r912; Neal and Simpson, 1920; Gilbert, 1933; Gerschickter 1945; Treves, 1954; Haagensen, 1956; Mitsuo

* Present address: Mount Vernon Hospital, Northwood, Middx.
Segi, 1960; and Bartlett, 196r). Whereas the incidence of breast carcinoma in the female is slowly rising, that in man appears constant (Mitsue Segi, 1960). The incidence in females also varię from country to country, and within a country, from race to race. However, in man the incidence is constant both from country to country and from race to race (Marsden, 1958; Mitsuo Segi, 1960.9.

Bilateral carcinomata of the breast in females rare: $0.6 \%$ of females present with simultaneous and $3 \%$ with consecutive bilateral primary carciner mata (Harrington, 1 946; Desaive, I 949; Reese, 1953; Guiss, 1954; Carrol and Shields, 1955 Farrow, 1956; Haagensen, 1956). The proportion of bilateral carcinomata in males is the same Treves and Holleb (1955) collected 146 cases male breast cancer and found one simultaneouss and three consecutive. The overall incidence of multiple carcinoma of any site is 2 to $4 \%$ (Ogifies I96r).

Paget's disease of the nipple forms $3 \%$ of ferite breast carcinoma (Ciprut, Roberts and Volk, $196 \mathrm{6}$ Sandison (1956) could only find I I recorded cases of Paget's disease in the male. Ciprut, Roberts an Volk (I96r) found 12 and added one of their ow (a negro).

\section{Etiology}

The ætiology of carcinoma of the male breast is unknown. About $25 \%$ have some family history of the condition, $15 \%$ have some endocrine abnot malilty but gynæcomastia is uncommon, and up to. $35 \%$ give a history of trauma (Sandison, $1956 \dot{q}$ Mohardt, 1956).

\section{Clinical Features}

Carcinoma of the male breast may present at any age with a peak incidence around 55 years. The sides are affected with equal frequency, $65 \%$ presen as a lump in the breast alone or combined witle bleeding, retracted nipple, encrustation or ulcern ation, axillary swelling or pain (Treves and Holleb, 1955). Skin involvement and deep attachment arê more common in the male than the female probably because the breast mass is so much smaller. The duration of symptoms (about one year) is longer than in women, perhaps due to less awareness botilit by doctor and patient.

In 80 to $90 \%$ the histology shows spheroidal celf or duct carcinoma, the rest being adenocarcinomat (Somerville, 1952; Treves and Holleb, 1955). bilateral cases the histology is usually the same or both sides. 


\section{Treatment}

It is generally agreed that surgery is the first line of treatment. In practice, however, 20 to $35 \%$ are inoperable due to metastases, fixity to the chest wall, ulceration or emaciation (Somerville, r 952 ; Treves and Holleb, 1955; Mohardt, 1956). Radical mastectomy is performed if possible, otherwise a simple mastectomy or local excision. Pre- or postoperative radiotherapy plays an important part but the prognosis for those treated by radiotherapy alone is poor (Mohardt, 1956). Orchidectomy is usually indicated by the appearance of metastases, but it is sometimes combined with simple mastectomy. Estrogens may be given for recurrences following orchidectomy and some remarkable results have been reported-e.g. Ogilvie, 1961but other reports suggest that tumour activity can be increased by both œstrogens and androgens (Schofield, 1957; Pyrah, 1956) combined orchidectomy and adrenalectomy with success, but medical adrenalectomy is more widely used.

\section{Prognosis}

The poor prognosis of carcinoma of the male breast is undoubtedly due to the high inoperability rate which is in turn due to the delay in diagnosis. Thus the overall five-year survival for men in most reported series (Somerville, 1952; Mohardt, 1956; Sandison, 1956) is only $30 \%$, but for the operable the figure is $42 \%$ (Sandison, 1956) and this compares favourably with the 34 to $48 \%$ quoted by Haagensen (1956) for women.

\section{Summary}

The case history of a 54-year-old man with simultaneous bilateral carcinoma of the breast with Paget's disease of one nipple is presented. The main features of carcinoma of the male breast are briefly reviewed.

It is a pleasure to acknowledge the help of Miss M. D. Snelling and Mr. R. S. Handley under whose care the patient was admitted.

\title{
REFERENCES
}

Bartlett, R. M. (196r): Carcinoma of the Breast-Personal Experiences with 185 Patients, Ann. Surg., 154, Suppl 306-314.

Carrol, W. W., and Shields, T. W. (1955): Bilateral Simultaneous Breast Cancer, A.M.A. Arch. Surg., 70, 672.

Ciprut, S., Roberts, T. W., and Volk, H. (196I): Paget's Carcinoma of the Male Breast-Case Report, Ann. Surg., 154, 1001 .

Desaive, P. (1949): Le Cancer Mammiare Bilateral, Y. Radiol. Electrol., 30, 335.

FARrow, J. H. (1956): Bilateral Mammary Cancer, Cancer, 9, 1182.

GeschickTER, C. F. (1945): 'Diseases of the Breast', and edition, pp. 616-632. Philadelphia, London and Montreal: J. B. Lippincott.

GilberT, J. B. (1933): Carcinoma of the Male Breast with Special Reference to Ætiology, Surg. Gynec. Obstet., 57, 451.

Guiss, L. W. (1954): The Problem of Bilateral Independent Mammary Carcinoma, Amer. $\dot{f}$. Surg., 88, I7I.

HaAgensen, C. D. (1956): 'Diseases of the Breast '. Philadelphia and London: W. B. Saunders.

HARRINGTON, S. W. (I946): Survival Rates of Radical Mastectomy for Unilateral and Bilateral Carcinoma of the Breast, Surgery, 19, 154.

MARSDEN, A. T. H. (1958): The Geographical Pathology of Cancer in Malaya, Brit. F. Cancer, 12, I61.

MITsuo SEgI (1960): 'Cancer Mortality for Selected Sites in 24 Countries'. Published by Department of Public Health, Tohoku University School of Medicine, Sendai, Japan.

Mohardt, J. H. (1956): Carcinoma of the Breast: Review of 36 Cases, Quart. Bull. Northw. Univ. med. Sch., $30,315$.

NEAL, M. P., and SimpSON, B. T. (1930): Diseases of the Male Breast, Missouri Med., 27, 565.

Ogilvie, T. A. (196I): Carcinoma of the Breast in a Male, Proc. roy. Soc. Med., 54, 814.

Pyrah, L. N. (1956): Hormones in the Treatment of Cancer of the Breast and Prostate, Brit. F. Surg., 44, 69.

ReESF, A. J. M. (1953): Bilateral Carcinoma of the Breast, Ibid., 40, 428.

Registrar General's Statistical Review of ENGLaNd and Wales (i960). London: H.M.S.O.

Sandison, A. T. (1956): Paget's Disease of the Male Breast, Brit. F. Surg., 44, 330.

Schofield, G. E. (1957): Bilateral Breast Carcinoma: Report of a Case and Review of Literature, Scot. med. F., 2, 306. Somerville, P. (1952): Carcinoma of the Breast: A Report of 19 Cases and Review of the Literature, Brit. $\ddot{\mathcal{F}}$. Surg., 39, 296.

Speese, J. (1912): Tumours of the Male Breast, Ann. Surg., 55, 530.

Treves, N. (1954): Paget's Disease of the Male Mamma: A Report of Two Cases, Cancer, 7, 325. and HolleB, A. I. (1955): Carcinoma of the Male Breast: A Report of 146 Cases, Ibid., 8, 1239.

\section{REVERSIBLE PSYCHOTIC SYNDROME}

\section{AFTER POTASSIUM PERCHLORATE TREATMENT}

\author{
G. Merikas, M.D., K. Vervesos, M.D., and S. Marketos, M.D. \\ Fourth Medical Unit, Evangelismos Hospital, Athens, Greece
}

Potassium perchlorate has been extensively used in the treatment of thyrotoxicosis since it has been shown to be an effective and relatively safe therapeutic agent (Godley and Stanbury, 1954; Morgans and Trotter, 1954, 1960; Crooks and Wayne, 1959, 1960). Nevertheless side-effects may occur and up to date the following reactions to this drug have been reported: gastrointestinal disturbances, 